\title{
Relationship between the expression of CD25 and CD69 on the surface of lymphocytes T and B from peripheral blood and bone marrow of patients with chronic lymphocytic leukemia and established prognostic factors of this disease
}

\author{
Ewelina Grywalska ${ }^{1, A-D, F}$, Małgorzata Bartkowiak-Emeryk',C, Marcin Pasiarski ${ }^{2,3, B}$, Karolina Olszewska-Bożek, \\ Michał Mielnik ${ }^{1, B}$, Martyna Podgajna ${ }^{1, B}$, Monika Pieczykolan ${ }^{1, C}$, Anna Hymos ${ }^{4, B}$, Elżbieta Fitas ${ }^{1, B}$,

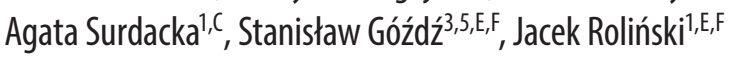 \\ ${ }^{1}$ Department of Clinical Immunology and Immunotherapy, Medical University of Lublin, Poland \\ 2 Department of Hematology, Holycross Cancer Center, Kielce, Poland \\ ${ }^{3}$ Faculty of Health Sciences, Jan Kochanowski University, Kielce, Poland \\ ${ }^{4}$ Department of Otolaryngology and Laryngeal Oncology, Medical University of Lublin, Poland \\ ${ }^{5}$ Department of Oncology, Holycross Cancer Center, Kielce, Poland \\ A - research concept and design; B - collection and/or assembly of data; $C$ - data analysis and interpretation; \\ $D$ - writing the article; $E$ - critical revision of the article; $F$ - final approval of the article
}

Address for correspondence

Ewelina Grywalska

E-mail: ewelina.grywalska@gmail.com

Funding sources

This work was supported by research grants NNo. UMO-2011/01/N/NZ6/1762, UMO-2012/05/B/ NZ6/00792 and UMO-2016/21/B/NZ6/02279

from the National Science Center (Poland),

and No. DS460 from the Medical University of Lublin (Poland).

Conflict of interest

None declared

Received on January 6, 2017

Reviewed on March 21, 2017

Accepted on June 6, 2017

DOI

10.17219/acem/74437

Copyright

Copyright by Author(s)

This is an article distributed under the terms of the

Creative Commons Attribution Non-Commercial License

(http://creativecommons.org/licenses/by-nc-nd/4.0/)

\begin{abstract}
Background. Chronic lymphocytic leukemia (CLL) is a condition characterized by the accumulation of morphologically mature monoclonal lymphocytes B with the $\mathrm{CD} 19+/ \mathrm{CD} 5+/ \mathrm{CD} 23+$ phenotype in lymphoid tissue, peripheral blood and bone marrow. The clinical course of patients with CLL is heterogeneous, ranging from indolent to aggressive. The role of lymphocyte activation in the natural history of $C L L$ is still a matter of discussion.
\end{abstract}

Objectives. The aim of this study was to determine the percentages and absolute numbers of lymphocytes $B$ and $T$ in peripheral blood and bone marrow of CLL patients. Moreover, we analyzed the relationship between the number of CD25-positive and CD69-positive lymphocytes and the established prognostic factors in CLL.

Material and methods. The study included 80 untreated patients with CLL and 20 healthy subjects. The immunophenotype of peripheral blood mononuclear cells (in both groups) and bone marrow cells (solely in the (LL group) was determined by means of flow cytometry.

Results. Patients with CLL showed a higher absolute number of activated lymphocytes B with phenotypes CD19+CD25 + and CD19+CD69+, as well as a higher absolute number of CD3+CD25+ lymphocytes T than the controls. The enhanced activation of peripheral blood and bone marrow lymphocytes was associated with higher Rai stages, an increased concentration of lactate dehydrogenase and beta-2 microglobulin and the progression of the disease. The number of lymphocytes B CD19+ZAP-70+ correlated positively with the number of CD19+CD25+ B cells and CD3+CD69+ T cells.

Conclusions. The study confirmed the association between an unfavorable prognosis and a high expression of activation markers in CLL patients. The determination of CD25+ and CD69+ lymphocytes T and B constitutes a valuable diagnostic tool, completing the cytometric evaluation of CLL.

Key words: flow cytometry, chronic lymphocytic leukemia, prognostic marker, lymphocyte count 


\section{Introduction}

Chronic lymphocytic leukemia (CLL) is a condition characterized by the accumulation of morphologically mature monoclonal lymphocytes B with the CD19+/CD5+/CD23+ phenotype in lymphoid tissue, peripheral blood and bone marrow. It is estimated that CLL constitutes $25-30 \%$ of all diagnosed leukemia cases, making it the most frequent malignancy of this type amongst adults from North America and Europe. ${ }^{1}$

The course of CLL is chronic by default. Of note, however, is its heterogeneity. Only $30 \%$ of the patients survive 10-20 years following the diagnosis. The remaining patients enter the terminal phase within the initial 5-10 years, despite an indolent onset of the condition. Individuals with the aggressive form of CLL survive only 2-3 years upon establishing the diagnosis. Spontaneous regression of CLL is of rare evidence. ${ }^{2}$ Treatment with various combinations of cytostatics and biological agents can induce remission, but a relapse occurs in most of the patients, making CLL an incurable condition.

Criteria allowing for distinguishing between low and high risk groups of CLL patients did not exist prior to the mid-1970s; subsequently, Rai et al., followed by Binet et al., proposed independent classification systems that are used to the present. ${ }^{3,4}$ According to Rai et al., patients are classified into 1 of 4 clinical stages ${ }^{3}$; in contrast, the classification by Binet et al. is comprised of 3 stages. ${ }^{4}$

The survival time of CLL patients differs across age categories. The younger the age at diagnosis, the more aggressive is the course of the leukemia. The proportion of CLL patients with Rai stage 2 or higher is larger in patients younger than 65 years and the loss of life expectancy in younger patients is more than twice as high as in older individuals. $^{5}$

Amongst other prognostic factors, lymphocyte doubling time (LDT) in untreated patients deserves special attention. Lymphocyte doubling time longer than 12 months is usually associated with a mild course of CLL; however, the shorter the LDT, the more aggressive is the phenotype of the disease. ${ }^{6-9}$ The concentration of beta- 2 microglobulin is another established prognostic factor: the higher the value of this parameter, the worse is the prognosis. ${ }^{10}$

Chronic lymphocytic leukemia cells differ in terms of the mutational status of genes encoding immunoglobulin heavy chain variable $(\operatorname{IgVH})$, which is correlated with the intracellular expression of $\zeta$-associated protein-70 (ZAP-70), the presence of the CD38 antigen and the degree of activation and susceptibility to apoptosis. ${ }^{11}$ Some of these cellular markers are the established prognostic factors in CLL. The prognosis is better in patients with mutated IgVH genes than in those without the mutation. ${ }^{12,13}$ A high expression of CD38 and ZAP-70 constitute a negative prognostic factor. ${ }^{14,15}$ Disorders of apoptosis are also postulated to play an important role in CLL, and the induction of programmed cell death by some medications is a determinant of successful therapy. ${ }^{16-18}$ However, the role of lymphocyte activation in the natural history of CLL is still a matter of discussion.

Most CLL patients develop hypogammaglobulinemia along with the disease progression. ${ }^{19,20}$ The detectable deficit can refer to both immunoglobulin $G$ class, and to $M$ and A classes. The deficiency develops irrespectively of the status of the established prognostic factors, such as the mutational status of IgVH. ${ }^{21}$

The role of chronic immunological stimulation and the resultant activation of lymphocytes $B$ in the pathogenesis of CLL has not been explained thus far. The in vivo activation of the lymphocytes is known to result from the presence of various antigens, including pathogens.

In a study of more than 77,000 initially healthy individuals, 129 participants developed CLL during an average period of 9.8 years. The authors studied the presence of monoclonal protein and immunoglobulin light chains in the blood samples of these patients, obtained prior to establishing the diagnosis. ${ }^{20}$ Amongst 61 individuals with a normal ratio of free light chains (FLC) $\kappa / \lambda$ and without monoclonal protein, 17 individuals showed elevated levels of FLC $\kappa / \lambda$, which suggests a polyclonal activation of lymphocytes B. These findings support the hypothesis involving chronic immunological stimulation in the pathogenesis of CLL.

De Fanis et al. analyzed the expression of CD95, the bestdescribed cell surface antigen associated with apoptotic pathways, on lymphocyte B before and after the in vitro induction of leukemia with phorbol-12-myristate 13-acetate (PMA), ionomycin, phytohemagglutinin, or myogen. ${ }^{22}$ The degree of activation was monitored on the basis of the early activation marker (CD69) expression. Chronic lymphocytic leukemia cells were revealed to be characterized by a markedly lower expression of CD95 than normal lymphocytes. Additionally, the leukemia cells were incapable of enhancing the expression of this molecule upon activation; although, it must be mentioned that such phenomenon was documented in the case of normal lymphocytes. Both CLL cells and normal lymphocytes showed a higher expression of CD69 after stimulation. Consequently, these findings suggest that CLL cells express the early activation marker to a similar extent as normal cells, but their activation-induced apoptosis is impaired. ${ }^{22}$

Compared to CD25-negative cells, lymphocytes B CD25+ release larger amounts of interleukin (IL)-6, IL-10 and interferon gamma (IFN $\gamma$ ) in response to the agonists of Toll-like receptors, are superior at presenting antigens to CD4+ cells, and are capable of a spontaneous synthesis of immunoglobulin classes A, G and M. Therefore, this subpopulation of lymphocytes B is postulated to correspond to mature, activated memory cells. ${ }^{6}$ Furthermore, Hassanein et al. revealed that the proportion of CLL cells expressing CD25, a marker of lymphocyte activation, was significantly higher in the ZAP70+ group compared with the ZAP70- group. ${ }^{23}$ 
The activation of lymphocytes B results from the synthesis of cytokines by activated T cells. Rossmann et al. analyzed the lymphocyte synthesis of cytokines, both spontaneous and induced by polyclonal activation. ${ }^{24}$ They observed that patients with the progressive form of CLL had significantly higher counts of $\mathrm{T}$ cells that spontaneously released IL-2, IL-4 and granulocyte-macrophage colony-stimulating factor (GM-CSF) as compared to healthy subjects and individuals with mild-course CLL. Also, an in vitro polyclonal activation of peripheral blood $\mathrm{T}$ lymphocytes was reflected by an increased fraction of the cells releasing the aforementioned cytokines, as well as tumor necrosis factor (TNF) and IFN- $\gamma$, both in patients with any form of CLL and in the controls. These findings suggest that lymphocytes $\mathrm{T}$ of individuals with CLL show relatively high functional efficiency. Therefore, the enhanced synthesis of cytokines in vivo is likely to result from the stimulation of lymphocytes $\mathrm{T}$, especially in the progressive form of the disease. In turn, the abovementioned cytokines are involved in processes of maintaining the growth of leukemic lymphocytes B. ${ }^{24}$

The aim of this study was to determine the percentages and absolute numbers of lymphocytes $\mathrm{B}$ and $\mathrm{T}$ in the peripheral blood and bone marrow of untreated CLL patients. We analyzed the relationship between the number of CD25- and CD69-positive lymphocytes and the established prognostic factors in CLL.

\section{Material and methods}

\section{Participants}

The study included 80 untreated patients with CLL diagnosed on the basis of clinical examination, morphological evaluation and immunophenotyping of peripheral blood and bone marrow lymphocytes. The control group comprised 20 healthy subjects (13 women and 7 men) in whom the immunophenotype of lymphocytes was determined in $10 \mathrm{~mL}$ samples of peripheral blood. The characteristics of the study participants are summarized in Table 1.

None of the participants used immunomodulating agents, showed signs of infection within 1 month prior to the study, underwent blood transfusion, or was diagnosed with an autoimmune condition or allergy.

Table 1. Characteristics of the study participants

\begin{tabular}{|c|c|c|c|c|}
\hline \multicolumn{2}{|l|}{ Parameter } & $\begin{array}{l}\text { Study group } \\
\qquad(\mathrm{n}=80)\end{array}$ & $\begin{array}{l}\text { Controls } \\
(n=20)\end{array}$ & p-value \\
\hline Gender & $\begin{array}{l}\text { women, n (\%) } \\
\text { men, n (\%) }\end{array}$ & $\begin{array}{l}38(47.5 \%) \\
42(52.5 \%)\end{array}$ & $\begin{array}{l}13(65 \%) \\
7(35 \%)\end{array}$ & - \\
\hline Rai stage, n (\%) & $\begin{array}{l}0 \\
\text { I } \\
\text { II } \\
\text { III } \\
\text { IV }\end{array}$ & $\begin{array}{c}29(36.25 \%) \\
20(25 \%) \\
20(25 \%) \\
7(8.75 \%) \\
4(5 \%)\end{array}$ & - & - \\
\hline Early stage & Rai stage 0-I, n (\%) & 49 (61.25\%) & - & - \\
\hline Late stage & Rai stage II-IV, n (\%) & $31(38.75 \%)$ & - & - \\
\hline Age [years] & median (range) & $65(32-85)$ & $62.5(34-73)$ & $N S^{*}$ \\
\hline Leukocytes $\left[1 \times 10^{9} / L\right]$ & median (range) & $32.2(12-110)$ & $7.02(4.23-9.63)$ & 0.0000000001 \\
\hline Lymphocytes $\left[1 \times 10^{9} / \mathrm{L}\right]$ & median (range) & $26.13(6.71-98.49)$ & $2.62(1.39-4.96)$ & 0.0000000001 \\
\hline Doubled lymphocyte count on follow-up & $\begin{array}{l}\text { yes, n (\%) } \\
\text { no, n (\%) }\end{array}$ & $\begin{array}{l}19(23.75 \%) \\
61(76.25 \%)\end{array}$ & - & - \\
\hline Lymphocyte doubling time [months] & median (range) & $10(1-20)$ & - & - \\
\hline Lymphocyte doubling time $<12$ months & $\begin{array}{c}\text { yes, } n \text { ( } \% \text { of those with doubling) } \\
\text { no, } n \text { ( } \% \text { of those without doubling) }\end{array}$ & $\begin{array}{l}15(78.95 \%) \\
4(21.05 \%)\end{array}$ & - & - \\
\hline Hemoglobin concentration [g/dL] & median (range) & $12.90(7.80-15.40)$ & $14.35(12.5-16.9)$ & 0.00064 \\
\hline Thrombocytes $\left[1 \times 10^{9} / \mathrm{L}\right]$ & median (range) & $188(62.67-447)$ & $281.5(186-403)$ & 0.00051 \\
\hline Beta-2-microglobulin [mg/dL] & median (range) & $2.72(0.19-11.60)$ & $1.58(0.13-2.12)$ & 0.00037 \\
\hline Lactate dehydrogenase [IU/L] & median (range) & $368(228-938)$ & $147(83-198)$ & 0.000026 \\
\hline Implementation of treatment on follow-up & $\begin{array}{l}\text { yes, n (\%) } \\
\text { no, n (\%) }\end{array}$ & $\begin{array}{l}33(41.25 \%) \\
47(58.75 \%)\end{array}$ & - & - \\
\hline Time between diagnosis and treatment [months] & median (range) & $3(0-73)$ & - & - \\
\hline Response, n (\% of the treated patients) & $\begin{array}{c}\text { complete/partial remission } \\
\text { progression/death } \\
\text { ongoing treatment }\end{array}$ & $\begin{array}{l}12(36.36 \%) \\
15(45.45 \%) \\
6(18.18 \%)\end{array}$ & $\begin{array}{l}- \\
- \\
-\end{array}$ & $\begin{array}{l}- \\
- \\
-\end{array}$ \\
\hline
\end{tabular}

* not statistically significant (NS). 
The protocol of the study was approved by the Local Bioethics Committee of the Medical University in Lublin. All participants gave their written informed consent prior to the start of any procedures.

\section{Blood and bone marrow samples}

Samples of peripheral blood $(20 \mathrm{~mL})$ were obtained from the basilic vein of all the CLL patients. Moreover, a bone marrow aspirate $(5 \mathrm{~mL})$ was obtained from the iliac crest during routine diagnostic procedures. Additionally, peripheral blood samples $(10 \mathrm{~mL})$ of the controls were examined. The material was collected into ethylenediaminetetraacetic acid (EDTA) tubes (aspiration and vacuum systems, Sarstedt AG \& Co. KG, Nümbrecht, Germany) and analyzed shortly thereafter.

\section{Isolation of mononuclear cells}

Peripheral blood and a bone marrow aspirate were diluted with $0.9 \%$ phosphate-buffered saline (PBS) without calcium $\left(\mathrm{Ca}^{2+}\right)$ or magnesium $\left(\mathrm{Mg}^{2+}\right)$ (Biochrom AG, Berlin, Germany) at a 1:1 and 1:2 ratio, respectively. The diluted material was built up with $3 \mathrm{~mL}$ of Gradisol L (specific gravity 1.077 g/mL; Aqua Medica, Białystok, Poland) and centrifuged in a density gradient at $700 \times \mathrm{g}$ for $20 \mathrm{~min}$. The obtained fraction of mononuclear cells of peripheral blood and bone marrow was collected with Pasteur pipettes and washed twice in PBS without $\mathrm{Ca}^{2+}$ or $\mathrm{Mg}^{2+}$ for $5 \mathrm{~min}$. Subsequently, the cells were suspended in $1 \mathrm{~mL}$ of PBS without calcium or magnesium, and counted in the Neubauer chamber or tested for viability in trypan blue solution (0.4\% Trypan Blue Solution, Sigma Pharmaceuticals, Croydon, UK).

\section{Flow cytometry}

FACSCalibur flow cytometer (Becton Dickinson, Franklin Lakes, USA) equipped with an argon laser emitting at $488 \mathrm{~nm}$ was used to determine the immunophenotype of the mononuclear cells of peripheral blood and bone marrow. The results were analyzed with CellQuest software (Becton Dickinson) and a CaliBRITE calibration set (Becton Dickinson) was used to optimize the flow cytometer settings. A total of 10,000 cells were acquired from each sample based on the lymphocytic gate forward-scattered light (FSC)/side-scattered light (SSC). "Purity" of the lymphocytic gate was verified on the basis of the cellular distribution in a CD45/CD14 coordinate system.

\section{Preparation of cells for cytometry}

Peripheral blood mononuclear cells were suspended in $\mathrm{PBS}$ at a concentration equal to $2 \times 10^{7}$ cells per $\mathrm{mL}$, and $50 \mu \mathrm{L}$ of the solution were placed in $5 \mathrm{~mL}$ Falcon tubes (Becton Dickinson). Subsequently, the cells were subjected
Table 2. Characteristics of fluorochrome-conjugated monoclonal antibodies used in the study

\begin{tabular}{|l|c|c|}
\hline \multicolumn{1}{|c|}{ Specificity } & Fluorochrome & $\begin{array}{c}\text { Manufacturer } \\
\text { anti-CD3 }\end{array}$ \\
\hline FITC/PE/PE-Cy5 & $\begin{array}{c}\text { BD Biosciences, } \\
\text { San Jose, USA }\end{array}$ \\
\hline anti-CD19 & FITC/PE/PE-Cy5 & BD Biosciences, USA \\
\hline anti-CD25 & PE/PE-Cy5 & BD Biosciences, USA \\
\hline anti-CD38 & FITC & BD Biosciences, USA \\
\hline anti-CD69 & PE/PE-Cy5 & BD Biosciences, USA \\
\hline anti-CD5/CD19 & FITC/PE & BD Biosciences, USA \\
\hline anti-CD45/CD14 & FITC/PE & BD Biosciences, USA \\
\hline anti-CD3/CD19 & FITC/PE & BD Biosciences, USA \\
\hline
\end{tabular}

to 2- or 3-chrome labeling with monoclonal antibodies, according to the manufacturer's protocols (Table 2).

Following 30-min incubation with monoclonal antibodies at $4^{\circ} \mathrm{C}$, the cells were washed with PBS containing $0.1 \%$ sodium azide and $1 \%$ fetal bovine serum, centrifuged at $700 \times \mathrm{g}$ for $5 \mathrm{~min}$, and fixed in $0.5 \mathrm{~mL}$ of $1 \%$ paraformaldehyde solution (Sigma Pharmaceuticals).

The results of the cytometric analysis were presented as a fraction of cells labeled with fluorochrome-conjugated monoclonal antibodies or as a mean fluorescence intensity (MFI), corresponding to the expression of a given antigen on a cellular surface.

\section{Intracellular ZAP-70 kinase detection}

The BD Perm/Wash buffer (Becton-Dickinson) and antiZAP-70 PE (Becton Dickinson) were added to the appropriate tubes and incubated for $15 \mathrm{~min}$ at room temperature in darkness. Finally, the cells were washed and analyzed by flow cytometry. For each analysis, 20,000 events were acquired and analyzed using CellQuest software (Becton Dickinson).

\section{Statistical analysis}

Normal distribution of continuous variables was tested using the Shapiro-Wilk test, and the homogeneity of their variances was verified with Levene's test and the F-test. Depending on their distribution, the statistical characteristics of continuous variables were presented as arithmetic means and standard deviations (SD), or as medians and ranges (min-max). The Mann-Whitney U-test or the Kruskal-Wallis test were used for intergroup comparisons of continuous variables. The power and direction of relationships between 2 continuous variables was determined using Pearson's coefficient of linear correlation (r). All calculations were carried out with STATISTICA v. 9 (StatSoft, Tulsa, USA) package, with the level of significance set at $\mathrm{p}<0.05$. To present the survival function, the KaplanMeier estimator (survival curve) was used. 


\section{Results}

\section{Number of activated lymphocytes T and B}

The immunophenotypes of basic subpopulations of peripheral blood lymphocytes in patients and healthy controls are presented in Table 3. Compared to healthy individuals, patients with CLL showed a higher absolute number of lymphocytes B with phenotypes CD19+CD25+ ( $\mathrm{p}=0.000016)$ and $\mathrm{CD} 19+\mathrm{CD} 69+(\mathrm{p}=0.0003)$. Moreover, they had a higher absolute number of CD3+CD25+ $(p=0.00047)$ as well as CD3+CD69+ lymphocytes $\mathrm{T}(\mathrm{p}=0.07)$, although this latter difference lacked statistical significance.

\section{Relationship between the fraction of activated cells in peripheral blood and bone marrow and the established prognostic factors in CLL}

We revealed that higher Rai stages of CLL were associated with the enhanced activation of B cells in peripheral blood ( $\mathrm{p}=0.018$ ). Specifically, patients with stage $0 \mathrm{CLL}$ showed a significantly lower percentage of CD19+CD25+ lymphocytes B in peripheral blood than those in Rai stage 3 (31.24\% vs 78.67\%, $\mathrm{p}=0.003)$, and patients with stage $2 \mathrm{CLL}$ showed a significantly lower percentage of CD19+CD25+ lymphocytes $B$ in peripheral blood than those in Rai stage 3 (50.24\% vs 78.67\%, p = 0.021) (Fig. 1A). Moreover, there was a significant association between the percentage of CD19+ $B$ cells in peripheral blood and the expression of the early marker of activation, CD69 ( $\mathrm{p}=0.005)$. Specifically, patients with Rai stage 3 showed a significantly higher percentage of CD19+CD69+ B cells (47.16\%) than those with CLL stages $0(18.13 \%, \mathrm{p}=0.009)$ and 2 (19.09\%, $\mathrm{p}=0.019)$ (Fig. 1B).

Furthermore, the number of CD19+CD69+ lymphocytes B in bone marrow was significantly associated with the CLL stage $(\mathrm{p}=0.023)$. Specifically, patients with Rai stage 3 showed a higher fraction of activated lymphocytes in bone marrow than those with Rai stage 0 (51.07\% vs $19.34 \%, \mathrm{p}=0.018$ ) and 2 (51.07\% vs $19.74 \%, p=0.006$ ) (Fig. 1C). Finally, there was a significant association between the fraction of CD3+CD25+ T cells and the stage of the disease $(p=0.029)$. The difference was particularly evident in the case of Rai stages 3 and 1 (36.78\% vs $13.01 \%, \mathrm{p}=0.003$ ) (Fig. 1D).

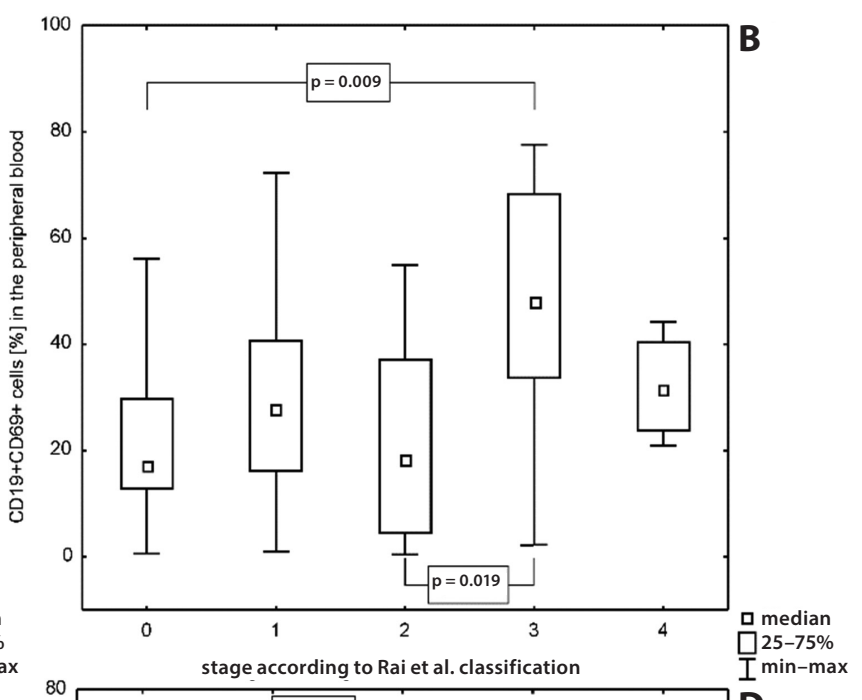

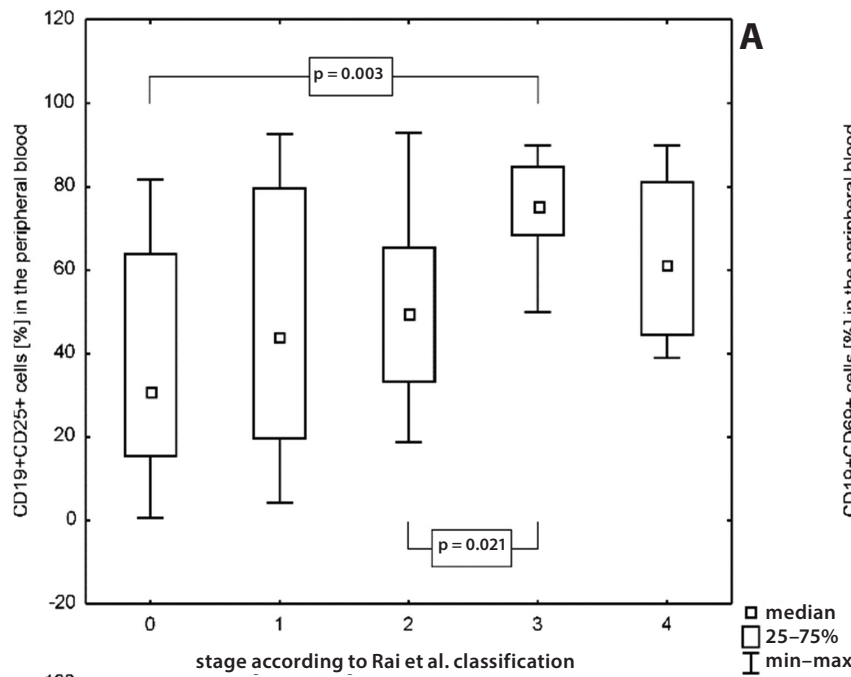
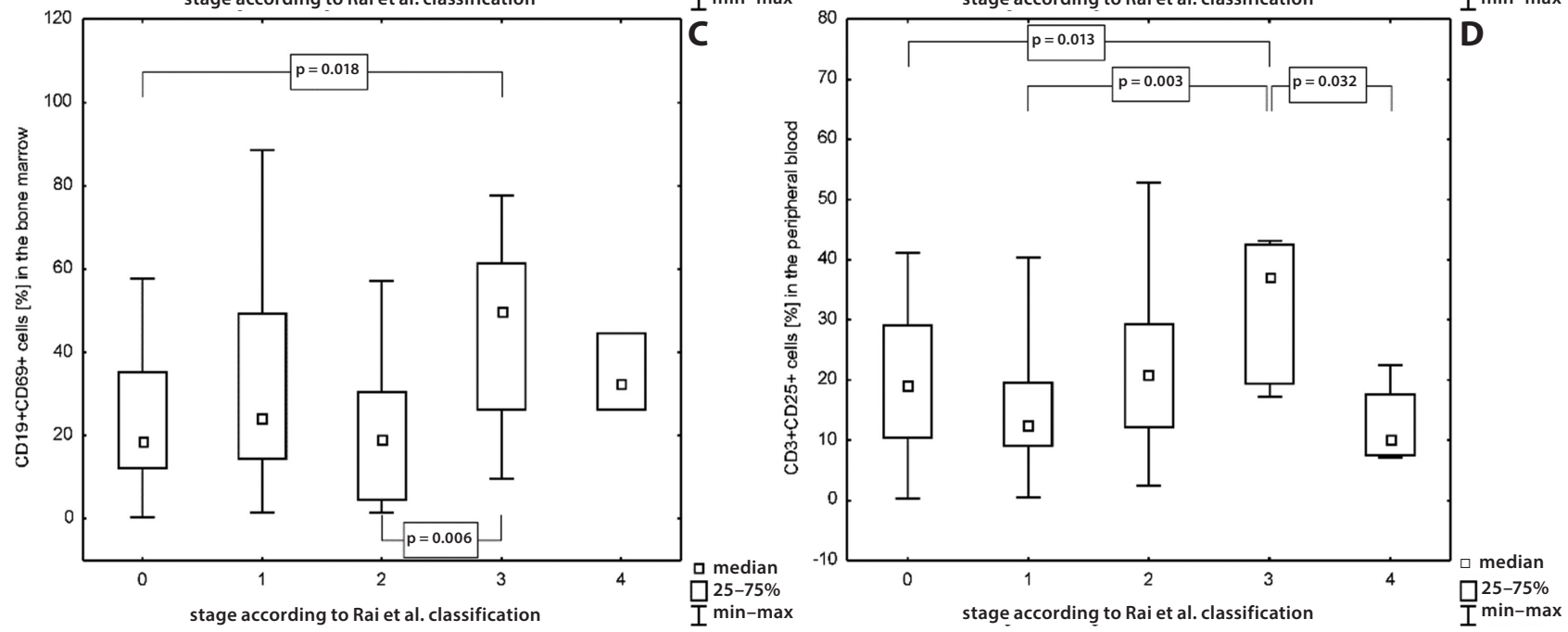

Fig. 1. Assessment of the frequencies of CD19+CD25+ cells in the peripheral blood of CLL patients with stage 0-4 according to Rai et al.'s classification (A); assessment of the frequencies of CD19+CD69+ cells in the peripheral blood of CLL patients with stage 0-4 according to Rai et al.'s classification (B); assessment of the frequencies of CD19+CD69+ cells in the bone marrow of CLL patients with stage 0-4 according to Rai et al.'s classification (C); assessment of the frequencies of CD3+CD25+ cells in the peripheral blood of CLL patients with stage 0-4 according to Rai et al.'s classification (D) 
Table 3. The immunophenotype of peripheral blood lymphocytes in the CLL patients and the controls; data presented as an absolute number of cells $\left(10^{3} / \mathrm{mm}^{3}\right)$

\begin{tabular}{|c|c|c|c|c|}
\hline \multicolumn{2}{|l|}{ Parameter } & CLL patients & Controls & $\mathrm{p}$-value \\
\hline CD19+/ZAP-70+ $\left[10^{3} / \mathrm{mm}^{3}\right]$ & median (min-max) & $12.28(0.91-64.19)$ & \multirow{4}{*}{-} & \multirow{4}{*}{-} \\
\hline ZAP-70+ (patients with $>20 \%$ or $<20 \%$ of ZAP-70+ B cells) & $\begin{array}{l}>20 \% \text { of } B \text { cells } \\
<20 \% \text { of } B \text { cells }\end{array}$ & $\begin{array}{l}22(27.5 \%) \\
58(72.5 \%)\end{array}$ & & \\
\hline $\mathrm{CD} 19+/ \mathrm{CD} 38+\left[10^{3} / \mathrm{mm}^{3}\right]$ & median (min-max) & $4.61(0.06-91.00)$ & & \\
\hline CD38+ (patients with $>20 \%$ or $<20 \%$ of CD38+ B cells) & $\begin{array}{l}>20 \% \text { of } B \text { cells } \\
<20 \% \text { of } B \text { cells }\end{array}$ & $\begin{array}{l}27(33.75 \%) \\
53(66.25 \%)\end{array}$ & & \\
\hline $\mathrm{CD} 3+\left[10^{3} / \mathrm{mm}^{3}\right]$ & median (min-max) & $2.25(0.16-17.31)$ & $1.69(0.96-3.27)$ & $\mathrm{NS}^{*}$ \\
\hline $\mathrm{CD} 19+\left[10^{3} / \mathrm{mm}^{3}\right]$ & median (min-max) & $21.84(4.90-90.68)$ & $0.33(0.11-0.50)$ & 0.000000003 \\
\hline $\mathrm{CD} 5+/ \mathrm{CD} 19+\left[10^{3} / \mathrm{mm}^{3}\right]$ & median (min-max) & $20.80(1.67-89.56)$ & $0.10(0.03-0.25)$ & 0.0000000001 \\
\hline $\mathrm{CD} 19+/ \mathrm{CD} 25+\left[10^{3} / \mathrm{mm}^{3}\right]$ & median (min-max) & $11.50(0.05-63.84)$ & $0.08(0.01-0.20)$ & 0.000016 \\
\hline $\mathrm{CD} 19+/ \mathrm{CD} 69+\left[10^{3} / \mathrm{mm}^{3}\right]$ & median (min-max) & $6.09(0.04-64.81)$ & $0.02(0.01-0.08)$ & 0.0003 \\
\hline $\mathrm{CD} 3+/ \mathrm{CD} 25+\left[10^{3} / \mathrm{mm}^{3}\right]$ & median (min-max) & $5.12(0.10-45.53)$ & $0.18(0.04-0.48)$ & 0.00047 \\
\hline $\mathrm{CD} 3+/ \mathrm{CD} 69+\left[10^{3} / \mathrm{mm}^{3}\right]$ & median (min-max) & $0.70(0.03-25.28)$ & $0.05(0.01-0.10)$ & $\mathrm{NS}^{*}$ \\
\hline
\end{tabular}

* not statistically significant (NS).
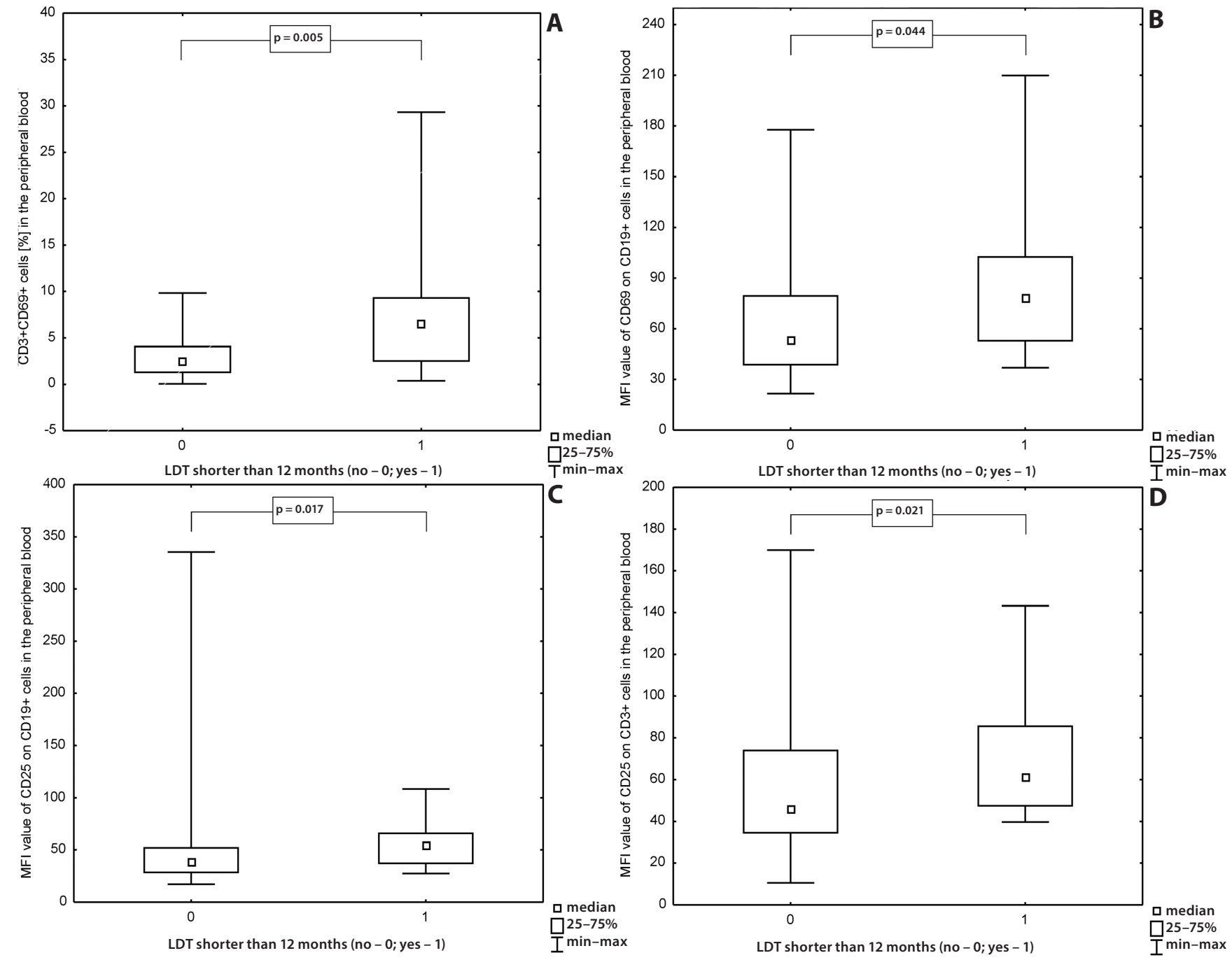

Fig. 2. Assessment of the frequencies of CD3+CD69+ cells in the peripheral blood of CLL patients in correlation with LDT (A); assessment of the CD69 MFI values on CD19+ cells in the peripheral blood of CLL patients in correlation with LDT (B); assessment of the CD25 MFI values on CD19+ cells in the peripheral blood of CLL patients in correlation with LDT (C); assessment of the CD25 MFI values on CD3+ cells in the peripheral blood of CLL patients in correlation with LDT (D) 

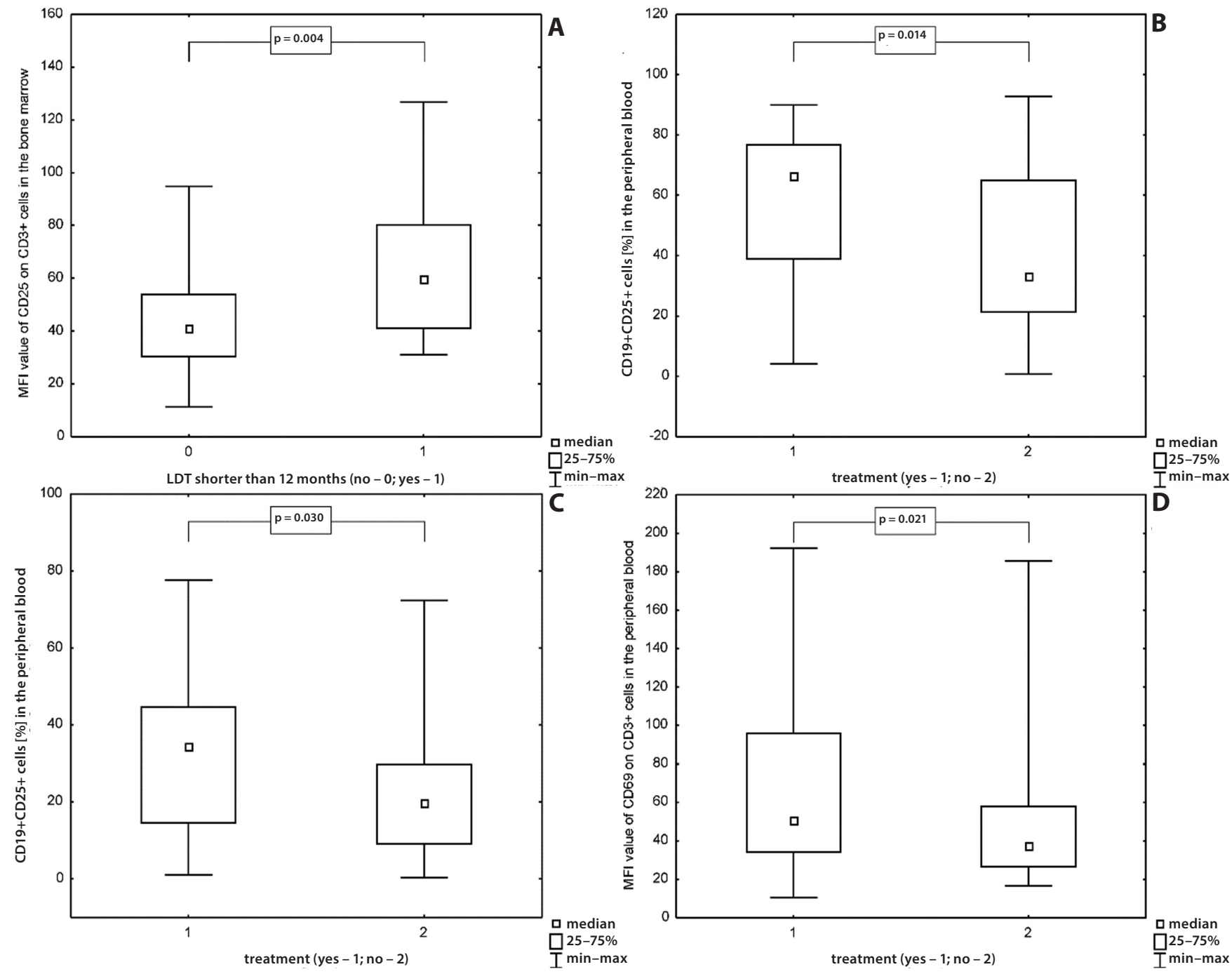

Fig. 3. Assessment of the CD25 MFI values on CD3+ cells in the bone marrow of CLL patients in correlation with LDT (A); assessment of the frequencies of CD19+CD25+ cells in the peripheral blood among 2 groups of CLL patients: those who received a treatment or the untreated individuals (B); assessment of the frequencies of CD19+CD69+ cells in the peripheral blood among 2 groups of CLL patients: those who received a treatment or the untreated individuals (C); assessment of the CD69 MFI values on CD3+ cells in the peripheral blood among the 2 groups of CLL patients: those who received a treatment or the untreated individuals (D)

The concentration of lactate dehydrogenase (LDH) correlated positively with the percentage of lymphocyte B CD19+CD25+ $(\mathrm{r}=0.248 ; \mathrm{p}=0.035)$ and $\mathrm{CD} 19+\mathrm{CD} 69+$ $(\mathrm{r}=0.243 ; \mathrm{p}=0.033)$, and lymphocyte T CD3+CD69+ $(r=0.308 ; p=0.008)$ of peripheral blood, as well as with lymphocyte B CD19+CD69+ of bone marrow $(r=0.298$; $p=0.011)$. Moreover, the concentration of LDH was correlated positively with MFI of CD69 on lymphocyte B $(\mathrm{r}=0.391 ; \mathrm{p}=0.0004)$, and MFI of CD25 $(\mathrm{r}=0.537$; $\mathrm{p}=0.0001)$ and $\operatorname{CD} 69(\mathrm{r}=0.349 ; \mathrm{p}=0.002)$ on lymphocyte $\mathrm{T}$ in peripheral blood, as well as with MIF of CD25 on lymphocyte $\mathrm{T}$ in bone marrow $(\mathrm{r}=0.382 ; \mathrm{p}=0.001)$.

The concentration of beta- 2 microglobulin showed a positive correlation with MFI of CD25 and CD69 on lymphocyte $\mathrm{T}$ in peripheral blood $(\mathrm{r}=0.289 ; \mathrm{p}=0.014$ and $\mathrm{r}=0.286 ; \mathrm{p}=0.015$, respectively), as well as with MFI of CD25 on lymphocyte $\mathrm{T}$ in bone marrow $(\mathrm{r}=0.393$; $\mathrm{p}=0.001)$.
We observed a significant negative correlation between the fraction of CD3+CD69+ lymphocyte $\mathrm{T}$ in peripheral blood and LDT $(r=-0.558 ; \mathrm{p}=0.016)$. The mean fluorescence intensity of CD69 on CD19+ cells of peripheral blood was inversely correlated with LDT $(r=-0.494 ; p=0.032)$. Additionally, LDT correlated inversely with MFI of CD25 on lymphocytes $\mathrm{B}(\mathrm{r}=-0.654 ; \mathrm{p}=0.002)$ and $\mathrm{T}(\mathrm{r}=-0.680$; $\mathrm{p}=0.002)$ in peripheral blood, as well as on lymphocyte $\mathrm{T}$ in bone marrow $(r=-0.636 ; \mathrm{p}=0.005)$. Patients who experienced lymphocyte doubling in less than 12 months had a higher percentage of CD3+CD69+ lymphocyte $\mathrm{T}$ than those who did not $(7.31 \%$ vs $2.49 \%, \mathrm{p}=0.005)$ (Fig. $2 \mathrm{~A}$ ), a higher MFI value of CD69 on the surface of B CD19+ lymphocytes ( 79.35 vs $54.17, \mathrm{p}=0.044$ ) (Fig. $2 \mathrm{~B}$ ), a higher MFI value of CD25 on the surface of B CD19+ lymphocytes (52.02 vs 39.91, $\mathrm{p}=0.017$ ) (Fig. $2 \mathrm{C}$ ), and a higher MFI value of CD25 on the surface of T CD3+ lymphocytes (61.47 vs 43.16, $\mathrm{p}=0.021$ ) (Fig. $2 \mathrm{D}$ ) in peripheral blood. 

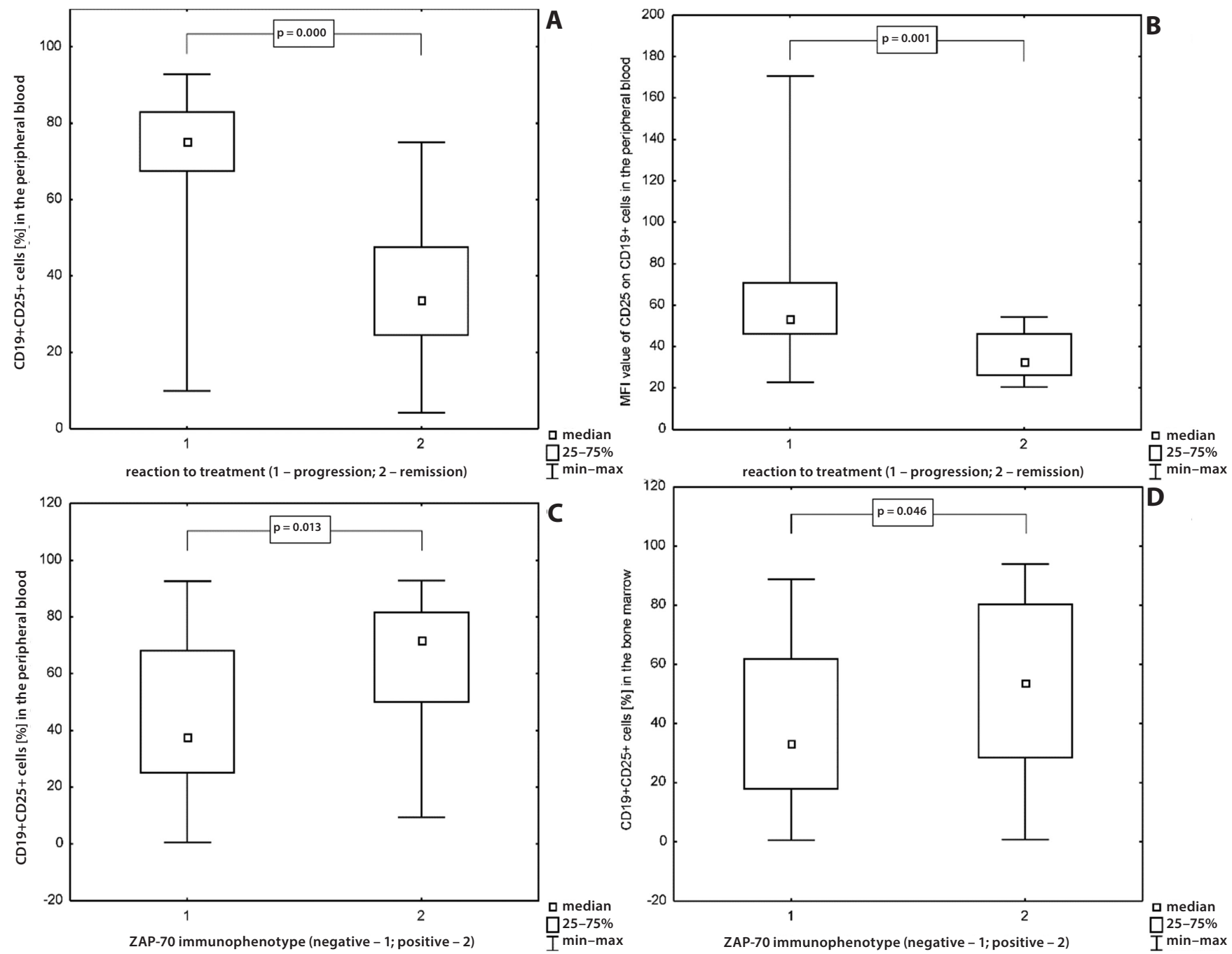

Fig. 4. Assessment of the frequencies of CD19+CD25+ cells in the peripheral blood of CLL patients with disease progression or remission reflected by the treatment (A); assessment of the CD25 MFI values on CD19+ cells in the peripheral blood of CLL patients with disease progression or remission reflected by the treatment (B); assessment of the frequencies of CD19+CD25+ cells in the peripheral blood of CLL patients with ZAP-70 positive or negative immunophenotype (C); assessment of the frequencies of CD19+CD25+ cells in the bone marrow of CLL patients with ZAP-70 positive or negative immunophenotype (D)

Patients who experienced lymphocyte doubling in less than 12 months had a higher MFI value of CD25 on the surface of T CD3+ lymphocytes in bone marrow than those who did not (60.04 vs 41.83, $\mathrm{p}=0.004$ ) (Fig. 3A).

We observed that patients who started therapy due to rapid progression of the disease had a significantly higher percentage of CD19+CD25+ B cells in peripheral blood compared to untreated individuals $(67.46 \%$ vs $33.91 \%, \mathrm{p}=0.014$ ) (Fig. 3B). Moreover, these patients showed a higher percentage of lymphocyte B CD19+CD69+ (34.03\% vs 20.15\%, p = 0.03) (Fig. 3C) and a higher MFI of CD25 on lymphocyte $\mathrm{T}$ ( 51.46 vs $38.97, \mathrm{p}=0.021)$ in peripheral blood (Fig. 3D).

Individuals in whom treatment was reflected by remission were characterized by a lower percentage of lymphocyte B CD19+CD25+ in peripheral blood than those who experienced progression and/or died (34.18\% vs $75.03 \%$, $\mathrm{p}=0.00013$ ) (Fig. 4A). The mean fluorescence intensity of CD25 on the surface of lymphocyte B of peripheral blood was significantly higher in patients in whom treatment was reflected by progression and/or death than in those who showed remission (52.19 vs 32.07, $\mathrm{p}=0.001$ ) (Fig. 4B). The individuals whose lymphocyte $B$ showed the expression of ZAP-70+ had higher frequencies of CD19+CD25+ $\mathrm{B}$ cells in peripheral blood $(71.12 \%$ vs $36.98 \%, \mathrm{p}=0.013)$ (Fig. 4C) and bone marrow (53.24\% vs $32.16 \%, \mathrm{p}=0.046$ ) compared to ZAP-70- individuals (Fig. 4D).

The number of lymphocytes B CD19+ZAP-70+ correlated positively with the number of CD19+CD25+ B cells $(\mathrm{r}=0.386 ; \mathrm{p}=0.001)$ and CD3+CD69+ T cells $(\mathrm{r}=0.323$; $\mathrm{p}=0.005)$ in peripheral blood, as well as with the number of CD19+CD25+ B cells in bone marrow $(r=0.307$; $\mathrm{p}=0.007)$.

The mean fluorescence intensity of CD25 on lymphocyte $\mathrm{T}$ of peripheral blood $(\mathrm{r}=0.314 ; \mathrm{p}=0.006)$ and bone marrow ( $\mathrm{r}=0.298 ; \mathrm{p}=0.012$ ), and MFI of CD25 on the surface of lymphocyte B of bone marrow ( $r=0.244$; $p=0.036$ ) increased proportionally to the fraction of CD19+ZAP-70+ 

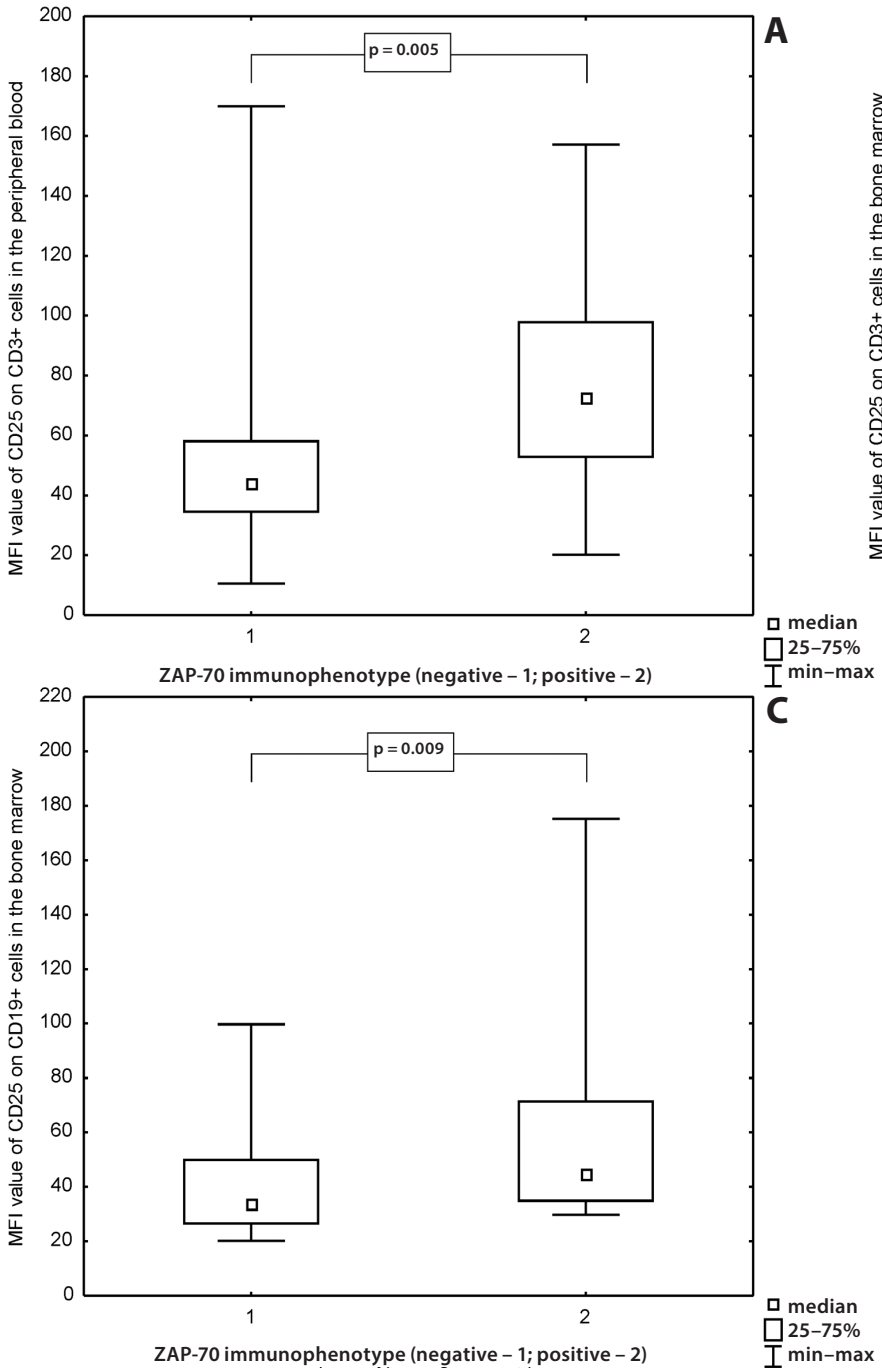

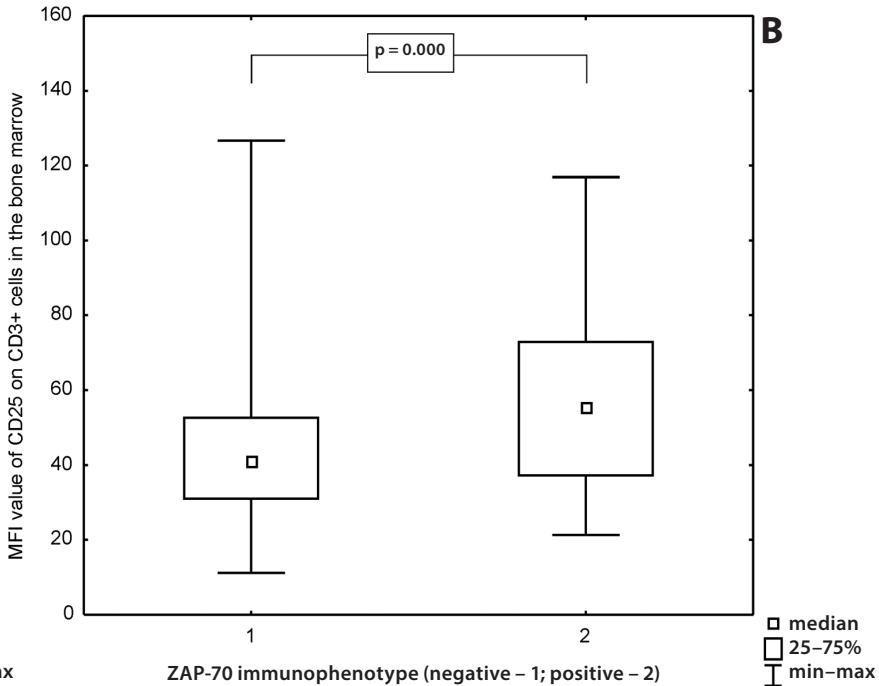

Fig. 5. Assessment of the CD25 MFI values on CD3+ cells in the peripheral blood of CLL patients with ZAP-70 positive or negative immunophenotype (A); assessment of the CD25 MFI values on CD3+ cells in the bone marrow of CLL patients with ZAP-70 positive or negative immunophenotype (B); assessment of the CD25 MFI values on CD19+ cells in the bone marrow of CLL patients with ZAP-70 positive or negative immunophenotype (C)

B cells. The mean fluorescence intensity of CD25 on the surface of lymphocyte $\mathrm{T}$ in peripheral blood (71.01 vs 42.14, $\mathrm{p}=0.005$ ) (Fig. 5A) and lymphocyte $\mathrm{T}$ in bone marrow (56.11 vs 41.63, $\mathrm{p}=0.00012$ ) (Fig. 5B), and on the surface of $\mathrm{B}$ cells in bone marrow (44.17 vs $32.81, \mathrm{p}=0.009$ ) was higher in patients with ZAP-70+ lymphocyte B (Fig. 5C).

\section{Relationship between the fraction of activated cells in peripheral blood and the probability of survival after the diagnosis of CLL}

We revealed factors that significantly increase the probability of survival after the diagnosis of the disease in the study group. The patients with the percentage of CD19+/ CD25+ lymphocytes $<56 \%(\mathrm{p}=0.0002)$ (Fig. 6A) and the absolute number of CD19+/CD25+ lymphocytes $<12.5 \times 10^{3}$ cells $/ \mu \mathrm{L}(\mathrm{p}=0.0295)$ (Fig. $6 \mathrm{~B})$, as well as the absolute number of CD19+/CD69+ lymphocytes $<7.7 \times 10^{3}$ cells $/ \mu \mathrm{L}$ $(\mathrm{p}=0.0047)($ Fig. 6C) and the percentage of CD19+/CD69+ lymphocytes $<29.65 \%$ ( $\mathrm{p}=0.0001$ ) (Fig. 6D) demonstrated increased survival.

Additionally, an absolute count of CD3+/CD69+ lymphocytes $<0.65 \times 10^{3}$ cells $/ \mu \mathrm{L}(\mathrm{p}=0.0205)$ constituted a positive survival factor (Fig. 7A).

A major factor that increased the probability of doubling the lymphocyte count was a percentage of CD19+/ CD25+ cells $>29.65 \%$ ( $\mathrm{p}=0.0191$ ) (Fig. 7B). An absolute count of CD19+/CD25+ lymphocytes $>12.5 \times 10^{3}$ cells $/ \mu \mathrm{L}$ was also a factor that increased the likelihood of doubling of the lymphocytosis $(\mathrm{p}=0.0246)$ (Fig. 7C).

\section{Discussion}

Chronic lymphocytic leukemia results from the expansion of mature lymphocytes B CD5+. Probably, these cells proliferate in bone marrow and in the lymph nodes, while 

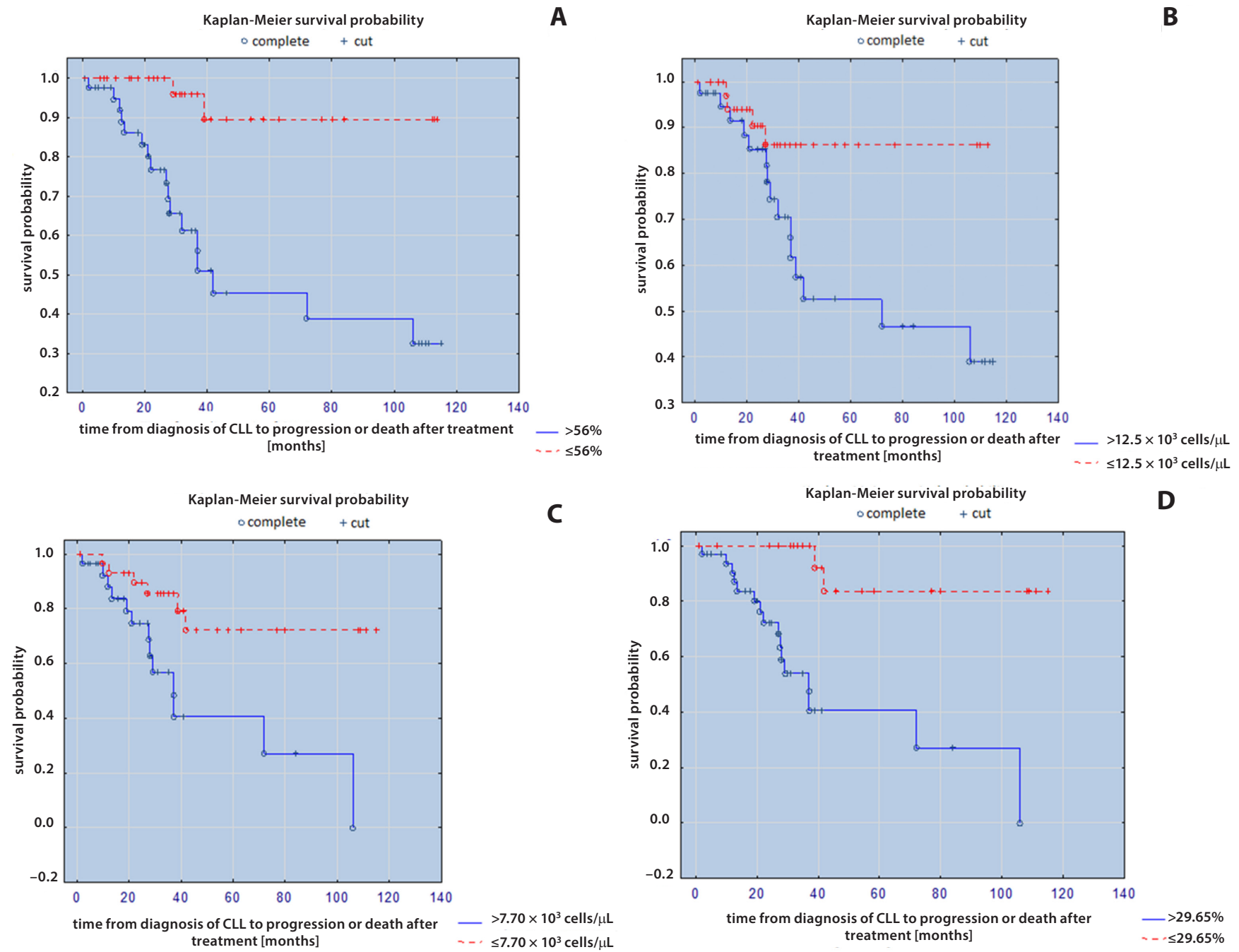

Fig. 6. Assessment of the survival probability with the time from diagnosis of CLL to progression or death after treatment in correlation with the percentage of CD19+/CD25+ cells (A); assessment of the survival probability with the time from diagnosis of CLL to progression or death after treatment in correlation with the absolute number of CD19+/CD25+ cells (B); assessment of the survival probability with the time from diagnosis of CLL to progression or death after treatment in correlation with the percentage of CD19+/CD69+ cells (C); assessment of the survival probability with the time from diagnosis of CLL to progression or death after treatment in correlation with the absolute number of CD19+/CD69+ cells (D)

the leukemic lymphocytes of peripheral blood remain at the G0/G1 phase. The expression of genes in leukemic cells resembles that of memory B lymphocytes; moreover, they express cell surface antigens specific to lymphocyte $B$ which had contact with an antigen (CD23, CD27, IgM, and IgD). ${ }^{25-27}$ The aim of the research, which has already continued for a significant number of years, is to identify subgroups of CLL patients with a similar clinical course of the disease. ${ }^{28} \mathrm{~A}$ high expression of ZAP-70 and CD38 was revealed to be associated with a more aggressive course of CLL. ${ }^{29}$

CD25, i.e., the alpha chain of the IL-2 receptor, is present on the surface of leukemic cells in $30-50 \%$ of CLL patients. The density of the expression of this molecule on leukemic cells is higher than on normal lymphocyte B, as well as on lymphocyte $\mathrm{B}$ during the so-called monoclonal B-cell lymphocytosis of undetermined significance (B-MLUS). ${ }^{30-34}$ CD25 is postulated to be associated with the activation status of cells expressing this antigen.
Probably, it also serves as a growth factor receptor and regulates the proliferation of lymphocyte B. ${ }^{35,36}$ Aside from CLL, a high expression of this molecule was also detected on the surface of B cells in promyelocytic and hair-cell leukemia. ${ }^{37,38}$ The expression of CD25 on the surface of lymphocytes and an elevated serum concentration of soluble CD25 are associated with a negative prognosis in acute lymphoblastic leukemia and diffuse large B-cell lymphoma. ${ }^{39,40}$ The data on the role of CD25 as a prognostic factor in CLL is inconclusive. Although according to some authors, the prognosis is worse in patients showing a high expression of CD25, other researchers observed that the CD25+ phenotype is associated with a milder course of CLL. ${ }^{31,33}$ The most recently published data from a retrospective study of 281 individuals with CLL followed-up for 8 years did not confirm a relationship between the expression of CD25 and the survival time or the time elapsed between diagnosis and the implementation of treatment. ${ }^{28}$ This study revealed that the expression 

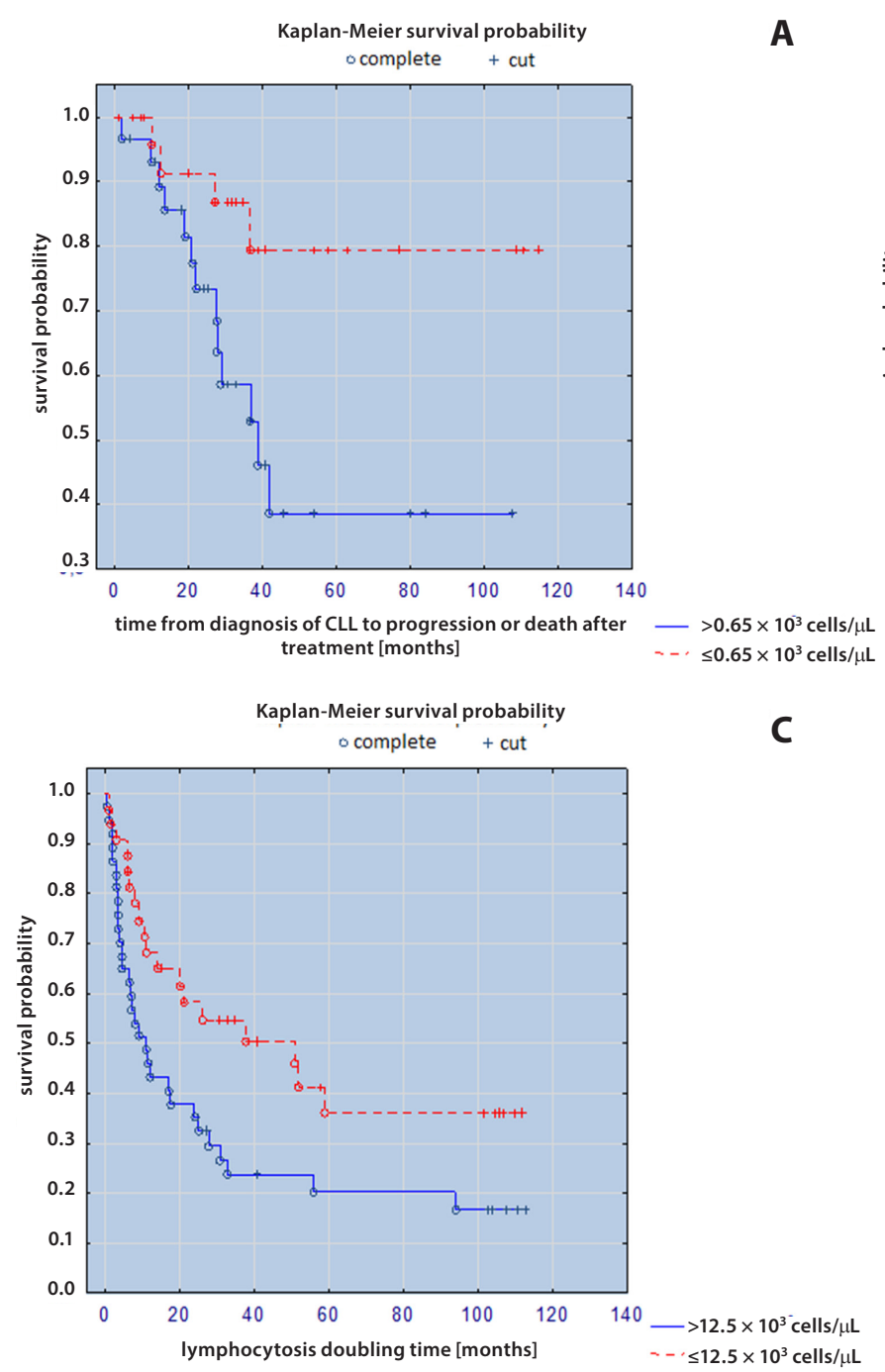

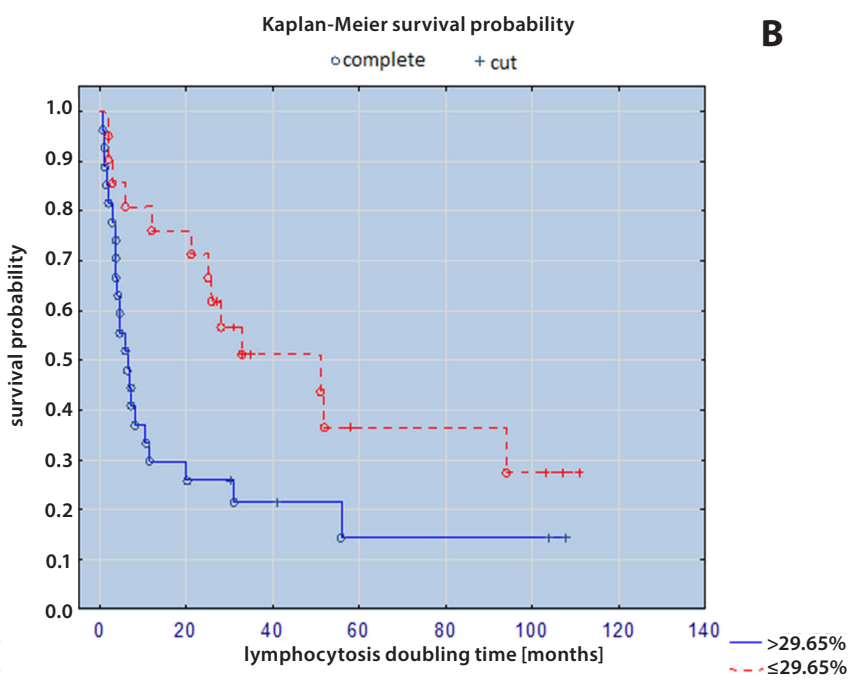

Fig. 7. Assessment of the survival probability with the time from diagnosis of CLL to progression or death after treatment in correlation with the absolute number of CD3+/CD69+ cells (A); assessment of the survival probability with LDT in correlation with the percentage of CD19+/CD25+ cells (B); assessment of the survival probability with LDT in correlation with the absolute number of CD19+/CD25+ cells (C)

of CD-25 on lymphocyte B of leukemia patients is many times higher than in the controls. Moreover, an association between the established prognostic factors in CLL and the CD25 expression was analyzed. The previously mentioned studies revealed a relationship between the number of lymphocytes B with the CD19+CD25+ phenotype and Rai clinical stage. The percentage of lymphocyte B CD19+CD25+ was higher in more advanced stages. Moreover, there was an inverse correlation between LDT and MFI of CD25 on lymphocyte B in peripheral blood, and a positive correlation between the concentration of LDH and the percentage of lymphocyte B CD19+CD25+ in peripheral blood. We revealed that the number CD19+CD25+ B cells in the peripheral blood of individuals who required treatment due to rapid progression of the disease was significantly higher than in untreated patients, which is contradictory to findings reported by Shvidel et al. ${ }^{28}$ Moreover, the patients who showed remission after the treatment were characterized by a higher percentage of lymphocyte B CD19+CD25+ in peripheral blood than individuals who experienced progression and/ or died. The mean fluorescence intensity of CD25 on the surface of lymphocyte B of peripheral blood was higher in individuals who showed progression and/or died after the treatment than in those with remission. Our analysis of the relationship between documented prognostic factors and the markers of activation revealed that the number of lymphocytes B CD19+ZAP-70+ correlated positively with the number of CD19+CD25+ B cells in peripheral blood and bone marrow. Moreover, MFI of CD25 on the surface of lymphocyte $B$ in bone marrow also increased proportionally to the number of CD19+ZAP-70+ cells. Individuals in whom the phenotype of lymphocytes $B$ was determined as ZAP-70+ had more CD19+CD25+ B cells in peripheral blood and bone marrow than patients whose lymphocytes did not show the expression of this marker. Also, MFI of CD25 on the surface of lymphocyte B in bone marrow was higher in individuals whose lymphocytes were 
classified as ZAP-70+. Similarly to Shvidel et al., our study did not reveal significant differences in the prevalence of anemia, thrombocytopenia and an elevated concentration of beta- 2 microglobulin between patients with a high and low number of CD25+ lymphocytes. ${ }^{28}$ Although our studied group was smaller than that analyzed by previously mentioned authors, the number of studied parameters was markedly higher. Plausibly, further extensive studies are needed to eventually verify the significance of the CD25 expression on leukemic lymphocytes in CLL.

Furthermore, our study also revealed that the expression of CD25 on lymphocyte $\mathrm{T}$ is higher in patients with CLL than in healthy individuals. Activated lymphocytes T of patients with CLL are known to stimulate the proliferation and promote the survival of leukemic cell clones, despite qualitative and quantitative disorders of their population. ${ }^{21}$ However, we did not find any literature evidence of the relationship between the lymphocyte $\mathrm{T}$ expression of CD25 and the prognostic factors in CLL. We revealed that a higher prevalence of CD3+CD25+ T cells was associated with higher Rai stages of CLL. Moreover, we observed an inverse correlation between LDT and MFI of CD25 on lymphocyte $\mathrm{T}$ of peripheral blood and bone marrow. Furthermore, the concentration of LDH and beta- 2 microglobulin also correlated positively with MFI of CD25 on lymphocyte $\mathrm{T}$ of peripheral blood and bone marrow. The mean fluorescence intensity of CD25 on lymphocyte $\mathrm{T}$ of peripheral blood and bone marrow increased proportionally to the percentage of CD19+ZAP-70+ B cells. We revealed that $Z A P-70+$ patients showed a significantly higher MFI of CD25 on lymphocyte T of peripheral blood and bone marrow. Moreover, MFI of CD25 was also significantly higher in individuals who required the implementation of treatment than in those who did not.

The expression of CD69 on activated cells can be observed early; namely, within $4 \mathrm{~h}$ of stimulation. As early as in 2002, Damle et al. revealed a significantly higher fraction of CD19+CD69+ lymphocytes in individuals without a mutation in IgVH genes and with the CD38+ phenotype of B cells. ${ }^{25}$ Similarly to normal lymphocytes, CLL cells can undergo activation, which can be determined on the basis of the CD69 expression. ${ }^{22}$ Our study of the expression of CD69 on leukemic cells revealed that higher Rai stages are associated with a higher prevalence of CD19+CD69+ lymphocyte $\mathrm{B}$, both in peripheral blood and in bone marrow. The mean intensity of fluorescence of CD69 on lymphocyte B of peripheral blood was inversely correlated with LDT. Moreover, we observed a positive correlation between the concentration of $\mathrm{LDH}$ and the percentage of CD19+CD69+ lymphocyte B of peripheral blood and bone marrow. Additionally, the concentration of LDH correlated positively with MFI of CD69 on lymphocyte B. Individuals in whom rapid progression of the disease required the implementation of treatment had a higher fraction of CD19+CD69+ lymphocyte B than untreated individuals. Aside from the expression of CD69 on B cells, we analyzed the relationship between the expression of this molecule on lymphocyte $\mathrm{T}$ and the established prognostic factors in CLL. We revealed an inverse correlation between the fraction of CD3+CD69+ lymphocyte T in peripheral blood and LDT. The density of the CD69 expression on lymphocyte $\mathrm{T}$ of peripheral blood was also inversely correlated with LDT. Moreover, we observed a positive correlation between the serum concentration of $\mathrm{LDH}$ and the percentage of CD3+CD69+ lymphocyte $\mathrm{T}$ in peripheral blood. A higher fraction of CD3+CD69+ lymphocytes was documented in patients with lymphocyte doubling. Also, the serum concentration of LDH and beta- 2 microglobulin correlated positively with MFI of CD69 on lymphocyte $T$ of peripheral blood. The number of CD19+ZAP-70+ lymphocytes B was associated with the number of CD3+CD69+ T cells in peripheral blood.

In conclusion, this study confirmed earlier findings on the association between a negative prognosis and a high expression of activation markers in CLL patients. The determination of CD25+ and CD69+ lymphocytes $\mathrm{T}$ and $\mathrm{B}$ constitutes a valuable diagnostic tool, completing the cytometric evaluation of CLL. Perhaps, aside from the established markers, such as CD38 and ZAP-70, the number of activated lymphocytes should also be determined in CLL patients, as this parameter supplements their prognosis. Further research is required in order to identify antigen(s) causing the activation of leukemic cells and normal lymphocytes $\mathrm{T}$.

\section{References}

1. Linet M, Schubauer-Berigan M, Weisenburger D, et al. Chronic lymphocytic leukaemia: An overview of aetiology in light of recent developments in classification and pathogenesis. Br J Haematol. 2007; 139(5):672-686. doi:10.1111/j.1365-2141.2007.06847.x

2. Thomas R, Ribeiro I, Shepherd $P$, et al. Spontaneous clinical regression in chronic lymphocytic leukaemia. Br J Haematol. 2002;116(2): 341-345. doi:10.1046/j.0007-1048.2001.03286.x

3. Rai KR, Sawitsky A, Cronkite EP, Chanana AD, Levy RN, Pasternack BS. Clinical staging of chronic lymphocytic leukemia. Blood. 1975;46(2): 219-234.

4. Binet J, Auquier A, Dighiero G, et al. A new prognostic classification of chronic lymphocytic leukemia derived from a multivariate survival analysis. Cancer. 1981;48(1):198-206.

5. Klepfish A, Rachmilewitz E, Sarid M, Schattner A. Evaluating the impact of age and disease on survival of chronic lymphocytic leukaemia patients by a new method. Int J Clin Pract. 2009;63(11):16011603. doi:10.1111/j.1742-1241.2009.02008.x

6. Amu S, Gjertsson I, Brisslert M. Functional characterization of murine CD25 expressing B cells. Scand J Immunol. 2010;71(4):275-282. doi:10. 1111/j.1365-3083.2010.02380.x

7. Karp M, Kosior K, Karczmarczyk A, et al. Cytotoxic activity of valproic acid on primary chronic lymphocytic leukemia cells. Adv Clin Exp Med. 2015;24(1):55-62. doi:10.17219/acem/29264

8. Pepper C, Majid A, Lin T, et al. Defining the prognosis of early stage chronic lymphocytic leukaemia patients. Br J Haematol. 2012;156(4): 499-507. doi:10.1111/j.1365-2141.2011.08974.x

9. Bazargan A, Tam C, Keating M. Predicting survival in chronic lymphocytic leukemia. Expert Rev Anticancer Ther. 2012;12(3):393-403. doi:10.1586/era.12.2

10. Wierda W, O'Brien S, Wang X, et al. Characteristics associated with important clinical end points in patients with chronic lymphocytic leukemia at initial treatment. J Clin Oncol. 2009;27(10):1637-1643. doi:10.1200/jco.2008.18.1701 
11. Rassenti L, Kipps T. Clinical utility of assessing ZAP-70 and CD38 in chronic lymphocytic leukemia. Cytometry B Clin Cytom. 2006;70(4): 209-213. doi:10.1002/cyto.b.20129

12. Martinelli S, Cuneo A, Formigaro L, et al. Identifying high-risk chronic lymphocytic leukemia: A pathogenesis-oriented appraisal of prognostic and predictive factors in patients treated with chemotherapy with or without immunotherapy. Mediterr J Hematol Infect Dis. 2016; 8(1):e2016047. doi:10.4084/MJHID.2016.047

13. Molica S, Shanafelt T, Giannarelli D, et al. The chronic lymphocytic leukemia international prognostic index predicts time to first treatment in early CLL: Independent validation in a prospective cohort of early stage patients. Am J Hematol. 2016;91(11):1090-1095. doi:10.1002/ajh. 24493

14. Karabon $\mathrm{L}$, Partyka $\mathrm{A}$, Jasek $\mathrm{M}$, et al. Intragenic variations in $B T L A$ gene influence mRNA expression of BTLA gene in chronic lymphocytic leukemia patients and confer susceptibility to chronic lymphocytic leukemia. Arch Immunol Ther Exp. 2016;64(S1):137-145. doi:10. 1007/s00005-016-0430-x

15. Kubeczko M, Nowara E, Spychałowicz W, et al. Efficacy and safety of vitamin D supplementation in patients with chronic lymphocytic leukemia. Postepy Hig Med Dosw (Online). 2016;70:534-541. doi:10. 5604/17322693.1202482

16. Grywalska E, Hymos A, Korona-Głowniak I, et al. Assessment of the influence of peripheral blood mononuclear cell stimulation with Streptococcus pneumoniae polysaccharides on expression of selected Toll-like receptors, activation markers and Fas antigen in patients with chronic lymphocytic leukemia. Postepy Hig Med Dosw (Online). 2016;70:959-967. doi:10.5604/17322693.1219399

17. Chiorazzi N, Rai K, Ferrarini M. Chronic lymphocytic leukemia. NEngl J Med. 2005;352(8):804-815. doi:10.1056/nejmra041720

18. Ziolkowska E, Wolowiec D, Cebula-Obrzut B, et al. Cytotoxic and apoptosis-inducing effects of bendamustine used alone and in combination with rituximab on chronic lymphocytic leukemia cells in vitro. Postepy Hig Med Dosw (Online). 2014;68:1433-1443. doi:10.5604/17322693.1130704

19. Andersen $M$, Vojdeman $F$, Andersen $M$, et al. Hypogammaglobulinemia in newly diagnosed chronic lymphocytic leukemia is a predictor of early death. Leuk Lymphoma. 2016;57(7):1592-1599. doi:10. 3109/10428194.2016.1142082

20. Tsai H, Caporaso N, Kyle R, et al. Evidence of serum immunoglobulin abnormalities up to 9.8 years before diagnosis of chronic lymphocytic leukemia: A prospective study. Blood. 2009;114(24):4928-4932. doi:10.1182/blood-2009-08-237651

21. Scrivener S, Goddard R, Kaminski E, Prentice A. Abnormal T-cell function in B-cell chronic lymphocytic leukaemia. Leuk Lymphoma. 2003;44(3): 383-389. doi:10.1080/1042819021000029993

22. De Fanis U, Romano C, Dalla Mora L, et al. Differences in constitutive and activation-induced expression of CD69 and CD95 between normal and chronic lymphocytic leukemia B cells. Oncol Rep. 2003;10(3): 653-658.

23. Hassanein N, Perkinson K, Alcancia F, Goodman B, Weinberg J, Lagoo A. A single tube, four-color flow cytometry assay for evaluation of ZAP-70 and CD38 expression in chronic lymphocytic leukemia. Am J Clin Pathol. 2010;133(5):708-717. doi:10.1309/ajcpqs4oxjj$\mathrm{sz} 5 \mathrm{kn}$

24. Rossmann E, Lewin N, Jeddi-Tehrani M, Osterborg A, Mellstedt H. Intracellular T cell cytokines in patients with B cell chronic lymphocytic leukaemia (B-CLL). Eur J Haematol. 2002;68(5):299-306. doi:10. 1034/j.1600-0609.2002.01612.x
25. Damle R, Ghiotto F, Valetto A, et al. B-cell chronic lymphocytic leukemia cells express a surface membrane phenotype of activated, antigen-experienced B lymphocytes. Blood. 2002;99(11):4087-4093. doi:10.1182/blood.v99.11.4087

26. Seifert M, Küppers R. Human memory B cells. Leukemia. 2016;30(12): 2283-2292. doi:10.1038/leu.2016.226

27. Rosenwald A, Alizadeh A, Widhopf G, et al. Relation of gene expression phenotype to immunoglobulin mutation genotype in $B$ cell chronic lymphocytic leukemia. J Exp Med. 2001;194(11):1639-1648. doi:10.1084/jem.194.11.1639

28. Shvidel L, Braester A, Bairey O, et al. Cell surface expression of CD25 antigen (surface IL-2 receptor alpha-chain) is not a prognostic marker in chronic lymphocytic leukemia: Results of a retrospective study of 281 patients. Ann Hematol. 2012;91(10):1597-1602. doi:10.1007/ s00277-012-1492-4

29. Moreno C, Montserrat E. New prognostic markers in chronic lymphocytic leukemia. Blood Rev. 2008;22(4):211-219. doi:10.1016/j.blre.2008. 03.003

30. Rivkina A, Holodnuka-Kholodyuk I, Murovska M, Soloveichika M, Lejniece S. Peripheral blood lymphocyte phenotype of ZAP-70(+) and ZAP-70(-) patients with B-cell chronic lymphocytic leukaemia. Exp Oncol. 2015;37(1):73-76.

31. Hjalmar V, Hast R, Kimby E. Cell surface expression of CD25, CD54, and CD95 on B- and T-cells in chronic lymphocytic leukaemia in relation to trisomy 12, atypical morphology and clinical course. Eur J Haematol. 2002;68(3):127-134. doi:10.1034/j.1600-0609.2002.01515.x

32. Ma ES. Recurrent cytogenetic abnormalities in non-Hodgkin's lymphoma and chronic lymphocytic leukemia. Methods Mol Biol. 2017; 1541:279-293. doi:10.1007/978-1-4939-6703-2_22

33. Amaya-Chanaga C, Rassenti L. Biomarkers in chronic lymphocytic leukemia: Clinical applications and prognostic markers. Best Pract Res Clin Haematol. 2016;29(1):79-89. doi:10.1016/j.beha.2016.08.005

34. Rawstron A, Shingles J, de Tute R, Bennett F, Jack A, Hillmen P. Chronic lymphocytic leukaemia (CLL) and CLL-type monoclonal B-cell lymphocytosis (MBL) show differential expression of molecules involved in lymphoid tissue homing. Cytometry B Clin Cytom. 2010;78(S1):S42S46. doi:10.1002/cyto.b.20534

35. Martkamchan S, Onlamoon N, Wang S, Pattanapanyasat K, Ammaranond $\mathrm{P}$. The effects of anti-CD3/CD28 coated beads and IL-2 on expanded T cell for immunotherapy. Adv Clin Exp Med. 2016;25(5): 821-828. doi:10.17219/acem/35771

36. Zuśka-Prot M, Jaroszewski J, Maślanka T. Involvement of regulatory T cells and selected cytokines in the pathogenesis of bronchial asthma. Postepy Hig Med Dosw (Online). 2016;70:668-677. doi:10.5604/ 17322693.1207511

37. Wotherspoon A, Attygalle A, Mendes LS. Bone marrow and splenic histology in hairy cell leukaemia. Best Pract Res Clin Haematol. 2015; 28(4):200-207. doi:10.1016/j.beha.2015.10.019

38. Janik J. Tumor markers in hairy cell leukemia. Leuk Lymphoma. 2011; 52(Suppl 2):69-71. doi:10.3109/10428194.2011.568651

39. Nakase $\mathrm{K}$, Kita $\mathrm{K}$, Miwa $\mathrm{H}$, et al. Clinical and prognostic significance of cytokine receptor expression in adult acute lymphoblastic leukemia: Interleukin-2 receptor a-chain predicts a poor prognosis. Leukemia. 2007;21(2):326-332. doi:10.1038/sj.leu.2404497

40. Oki Y, Kato H, Matsuo K, et al. Prognostic value of serum soluble interleukin-2 receptor level in patients with diffuse large B cell lymphoma, treated with CHOP- or RCHOP-based therapy. Leuk Lymphoma. 2008;49(7):1345-1351. doi:10.1080/10428190802108888 